\title{
Psychometric properties of the Chilean version of the Quick Disabilities of the Arm, Shoulder and Hand (Quick DASH) questionnaire for patients with shoulder disorders
}

\author{
Claudio Chamorro ${ }^{1,2,3}$, Danilo Alvares ${ }^{4}$, Soledad Berger ${ }^{5}$, Francesca Balocci ${ }^{6}$, Ximena Rodriguez ${ }^{6}$, Francisco Soza ${ }^{7}$ \\ 'Departamento de Ciencias de la Salud. Facultad de Medicina. Pontifica Universidad Católica de Chile. Santiago. Chile. Facultad Cs. de la Rehabilitacion. Universidad Andres \\ Bello, Santiago, Chile. ${ }^{3}$ Servicio de Kinesioterapia. Ambulatorio Clínica Las Condes. ${ }^{4}$ Departamento de estadística. Facultad de Matemáticas. Pontifica Universidad Católica de \\ Chile. Santiago. Chile. ${ }^{5}$ Servicio de Kinesiología. Clínica San Carlos de Apoquindo. Pontificia Universidad Católica de Chile. Santiago. Chile. ${ }^{\circ}$ Servicio de Kinesiología. Centro Médico \\ San Joaquín. Pontificia Universidad Católica de Chile. Santiago. Chile.'Departamento de Ortopedia y Traumatología. Pontificia Universidad Católica de Chile. Santiago. Chile.
}

doi: 10.18176/archmeddeporte.0004

Received: $16 / 08 / 2019$ Accepted: $26 / 05 / 2020$

Key words: Outcome measures. Reliability of results. Shoulder.

\section{Summary}

Introduction: The literature provides psychometric properties Quick Disabilities of the Arm, Shoulder and Hand (DASH) similar to the original DASH. The potential advantages of this instrument include the shorter time needed to answer it and the elimination of some less relevant items. The cross-cultural validity for the Chilean version of the Quick DASH has already been developed, but its psychometric properties have not yet been studied in the Chilean population.

Aim: To determine the internal consistency, test-retest reliability, minimum detectable change, minimum important change, relevant clinical change, and sensitivity of the Quick DASH subjective questionnaire in patients with common shoulder pathologies in the Chilean population.

Material and method: 81 patients with shoulder pathologies were recruited by completing the Quick DASH on 3 occasions. After visiting their attending physician, starting physical therapy, and after completing 10 sessions of physical therapy. Results: The questionnaire shows an internal consistency of 0.92, test-retest reliability of 0.95 (0.91-0.97), minimum detectable change of 19.6\%, minimum important change of $25.5 \%$, relevant clinical change of $37.1 \%$, and effect size (sensitivity) of 1.1 . Conclusions: The psychometric properties described show that the Quick DASH can be used reliably in both clinical and research for Chilean patients with shoulder pathologies.

\section{Resumen}

Introducción: Los cuestionarios basados en la percepción subjetiva del paciente sobre las disfunciones asociadas a su patología son comúnmente utilizado como instrumentos de evaluación, para definir manejo terapéutico y evaluar estados de avance tanto en la clínica como investigación. Es relevante que los cuestionarios seleccionados midan lo que proponen de manera válida y confiable, pero que además sea factible de utilizar considerando su simpleza como el tiempo empleado en su uso. Existen diversos cuestionarios comúnmente utilizados en las patologías de hombro. Entre estos se encuentra el cuestionario Quick Disabilities of the Arm, Shoulder and Hand (QuickDASH) que puede ser utilizado en diversas disfunciones de extremidad superior y está clasificado entre los mejores cuestionarios subjetivos autoadministrados considerando sus propiedades psicométricas. Las potenciales ventajas de este instrumento incluyen el menor tiempo necesario para contestarlo y la eliminación de algunos ítems menos relevantes. La validez transcultural para la versión chilena del Quick DASH ya ha sido desarrollada, pero sus propiedades psicométricas aún no han sido estudiadas en la población chilena.

Objetivo: Determinar la consistencia interna, confiabilidad test-retest, cambio mínimo detectable, cambio mínimo importante, cambio clínico relevante y sensibilidad del cuestionario subjetivo Quick DASH en pacientes con patologías de hombro en la población chilena.

Material y método: 81 pacientes con patologías de hombro fueron reclutados completando el Quick DASH en 3 ocasiones. Tras visitar al médico tratante, cuando comiencen su rehabilitación kinésica y tras completar 10 sesiones de kinesioterapia.

Palabras clave:

Confiabilidad de resultados.

Cuestionarios subjetivos autoadministrados. Hombro. Resultados: El cuestionario muestra una consistencia interna de 0.92, confiabilidad test-retest de 0.95 (0.91-0.97), cambio mínimo detectable de $19.6 \%$, cambio mínimo importante de $25.5 \%$, cambio clínico relevante de $37.1 \%$ y tamaño del efecto de 1.1 . Conclusiones: Las propiedades psicométricas demuestran que el Quick DASH puede ser usado de manera confiable tanto en clínica como en investigación para pacientes chilenos con patologías de hombro.

Correspondence: Claudio Chamorro

E-mail:cchamorrol@uc.cl 


\section{Introduction}

Shoulder-related pathologies constitute the third highest reason for muscular-skeletal injury consultancies in medical practice. Questionnaires based on the patient-reported outcome measure (PROM) linked to the pathology in question, are commonly-used assessment instruments to determine therapy options and to evaluate clinical and research states of progress ${ }^{1-3}$. It is important for clinicians and researchers to choose a PROM that is able to validly and reliably measure the element, whilst also being feasible for use considering its simple nature as well as the time invested in it. There are different commonly-used PROM for shoulder pathologies. One is the Quick Disabilities of the Arm, Shoulder and Hand questionnaire (Quick DASH), which can be used for different upper extremity dysfunctions ${ }^{4}$, and is positioned among the best PROM given its psychometric properties ${ }^{5-7}$. The Quick DASH comprises 11 questions addressing the degree of difficulty the patient experiences in performing physical activities due to shoulder, elbow or hand problems (6 questions); the intensity of pain and tingling sensation (2 questions); and the effects these problems have on the patient's social, work and sleep activity (3 questions). The cross-cultural validity of the Quick DASH into Spanish has been published8, but its psychometric properties have not yet been studied for the Chilean population. The aim of this study is to establish the internal consistency, test-retest reliability, minimal detectable change, minimal important change, relevant clinical change and sensitivity of the subjective Quick DASH questionnaire on patients with common shoulder pathologies in Chile.

\section{Material and method}

\section{Study type}

Internal consistency, test-retest reliability, minimal detectable change (MDC), minimal important change (MIC), relevant clinical change (RCC) and sensitivity of the Quick DASH questionnaire were all assessed on a cohort of Chilean patients with shoulder pathologies, via an observational analytical prospective test-retest study.

\section{Sample}

The patients were recruited from medical centres, hospitals and clinics in the Pontifical Catholic University of Chile Health Network between October 2018 and January 2019. The group considered for this study were patients with medically diagnosed shoulder pathologies from kinesiatrics. The exclusion criteria were those aged under 18 years, cervical pain of any origin, shoulder pain caused by radicular, vascular or neoplasia disorder, inability to complete the Quick DASH questionnaire due to cognitive alterations or language difficulties. The study was approved in accordance with the Helsinki Declaration principles and by the Pontifical Catholic University of Chile Medicine Faculty Ethics Committee. All the patients handed in their informed consent form before participating, and were free to leave the study whenever they wished (Table 1).

\section{Data collecting procedure}

The patients completed the Quick DASH questionnaire at 3 different times (T1, T2 and T3). T1, following a visit to the doctor treating the patient, T2, upon starting the kinesics rehabilitation, and T3, after completing 10 kinesiotherapy sessions. The patients were invited to participate by the doctor treating them. Upon accepting, they were given a questionnaire (T1) with written instructions and the informed consent to be completed and handed in to the kinesiologist treating them on the first session. In this session, patients completed the Quick DASH questionnaire for the second time (T2), and demographic data and medical diagnoses were obtained. All patients were also asked the first key question: How do you feel your symptoms have changed since the first time you filled out the questionnaire? The response options are: much better, quite better, somewhat better, the same, somewhat worse, quite worse, and much worse. With patients who answered the key question with "the same", the test-retest reliability of the Quick DASH and the minimal detectable change (Minimum detectable change (MDC) were analysed. In T3, when the patient completed session 10 of kinesiotherapy, the questionnaire was handed in again. When comparing $T 1$ and $T 3$, the instrument sensitivity was obtained via the size of effect. All patients were also asked the second key question: How do you feel your symptoms have changed since the first time you filled out the questionnaire? The response options are: much better, quite better, somewhat better, the same, somewhat worse, quite worse, and much worse. For patients that replied to the key question with "somewhat better", the minimal important change (MIC) in the questionnaire was also established, and those who replied with "quite better", the relevant clinical change (RCC) of the Quick DASH was established.

\section{Data collection instrument Quick DASH}

Each item is scored on a categoric scale with 5 response options, ranging from "no difficulty" or "no symptoms" (1 point) to "severe disability" or "severe symptoms" (5 points). The questions address the degree of difficulty experienced when performing physical activities due to the shoulder, elbow or hand problems (items 1-6), the effects of the upper extremity problems on social, work or sleep activity (items 7, 8, 11), the severity of the painful symptoms (item 8), and the severity of the tingling symptoms (item 10) in the shoulder, elbow and hand (items $9,11)$. These items provide the Quick DASH disability/symptoms score, ranging from zero (no disability) to 100 (severe disability). This score is obtained using the following equation:

Quick DASH $=[($ sum of $\mathrm{n}$ responses $/ \mathrm{n})-1] \times 25$, in which $n$ is the number of completed responses. The Quick DASH scoring cannot be calculated if there is more than 1 missing item.

\section{Statistical analysis}

For research linked to the study of the psychometric properties of instruments, a sample size of 5-10 patients is recommended for each item in the questionnaire. As the questionnaire comprises 11 items, and 
taking into account a $20 \%$ desertion rate, a sample size of 80 participants is suggested ${ }^{10}$.

The following psychometric properties were analysed:

\section{Internal consistency}

This was established using Cronbach alpha coefficient identified in T1. This coefficient assesses if there is a correlation in each item of the questionnaire with the Quick DASH total score. A value recommended for a health questionnaire is around $0.7^{11}$.

\section{Reliability Test-Retest}

This was established by comparing the Quick DASH score in T1 and $\mathrm{T} 2$ in patients that reported no changes in the key question consulted in T2. An instrument is considered reliable if it delivers similar results over time to each patient under the same conditions. To qualify the test-retest reliability, the intraclass correlation coefficient (ICC) was used. An ICC between 0.0 and 0.39 is classified as poor; between 0.40 and 0.59 as regular; between 0.60 and 0.74 as good, and between 0.75 and 1.00 as excellent reliability 10 . It is recommended for health-related questionnaires to have a score of at least 0.711 . To obtain the ICC, the 2 channel model with random effects was used. The Bland-Altman ${ }^{12}$ graph was used to analyse the distribution of the difference between the average scores from the T1 and T2 Quick DASH.

\section{Minimum detectable change (MDC)}

This is the minimal measurable change between the scores that represents a statistically significant difference over the margin of error of the measurement instrument under similar conditions ${ }^{13}$. To obtain it, the questionnaire scores from $\mathrm{T} 1$ and $\mathrm{T} 2$ in which patients responded to the first key question with "the same" were compared. First the standard error of measurement (SEMMDC) was calculated by dividing the standard deviation of the differences between T1 and $\mathrm{T} 2$ by the root of $2^{12}$. SEM is considered an absolute measure of error of measurement ${ }^{11}$. The MDC is calculated using the following formula: $\mathrm{MDC}=1.96 * \sqrt{2} * \mathrm{SEM}$ (considering $\mathrm{SEM}=$ standard deviation of the differences between the Quick DASH scores in T1 and T2/ $\sqrt{2}$ ).

The MDC establishes the interval which is within the margin of error of the instrument with $95 \%$ reliability and thereby the minimum variation in the questionnaire score that must be present to be considered statistically significant ${ }^{14}$. The difference in the Quick DASH score between $\mathrm{T} 1$ and $\mathrm{T} 2$ was contrasted with the average scores in the questionnaire using the Bland-Altman graph.

To express SEM as a percentage (SEM\%), the following formula was used:

(Differences between the Quick DASH in T1 and T2/Quick DASH score in $\mathrm{T} 1)^{*} 100$.

To express MDC as a percentage (MDC\%), the following formula was used: MDC $\%=1.96 * \sqrt{2} *$ SEM $\%$.

\section{Minimum important change (MIC)}

This is the minimal measurable change for the subject assessed to consider a slight improvement ${ }^{14}$. The calculation was performed with subjects that replied to the second key question with "somewhat better". First the standard error of measurement (SEMMIC) was calculated by dividing the standard deviation of the differences between $\mathrm{T} 1$ and $\mathrm{T} 3$ by the root of $2^{12}$. The MIC was calculated using the formula $M I C=1.96 * \sqrt{2} * S E M$, in which MIC is the minimum change present in an individual's Quick DASH score to ensure 95\% reliability that this change is linked to the patient's perceived improvement.

To express SEM as a percentage (SEM\%), the following formula was used:

\section{(Differences between the Quick DASH in T1 and T3/Quick DASH} score in $\mathrm{T} 1)^{*} 100$.

To express MIC as a percentage (MIC\%), the following formula was used:

$$
\text { MIC\%=1.96* } \sqrt{2} * \text { SEM } \% .
$$

\section{Relevant clinical change (RCC)}

This is the minimal possible change in the Quick DASH score for the subject assessed to consider a relevant improvement ${ }^{15}$. The calculation was only performed with subjects that replied to the second key question with "quite better". First the standard error of measurement (SEMRCC) was calculated by dividing the standard deviation of the differences between $\mathrm{T} 1$ and $\mathrm{T} 3$ by the root of $2^{13}$. The RCC was calculated using the formula $R C C=1.96^{*} \sqrt{2} * S E M$, in which $R C C$ is the minimum change present in an individual's Quick DASH score to ensure $95 \%$ reliability that this change is linked to the patient's perceived relevant improvement. To express SEM* as a percentage (SEM\%), the following formula was used:

(Differences between the Quick DASH in T1 and T3/Quick DASH score in $T 1)^{*} 100$

To express RCC as a percentage (RCC\%), the following formula was used:

$$
\text { RCC } \%=1.96 * \sqrt{ } 2 * \text { SEM } \%
$$

\section{Sensitivity}

Sensitivity was expressed using the size of the effect (difference in the Quick DASH score between T1 and T3/standard deviation of the differences between T1 and T3). If the size of the effect is near 0.2 , it is considered small, 0.5 is considered moderate, and around 0.8 high $^{15}$.

An analysis of the patients' demographic characteristics and data regarding the different psychometric properties of the Quick DASH questionnaire was performed using the SPSS 25 statistics programme.

\section{Results}

81 patients participated in the study and completed the Quick DASH in T1. Their demographic characteristics are displayed in Table 1 and the psychometric properties of the Quick DASH are in Table 2. Figure 1 displays the Bland Altman graph to contrast the difference between T1 and T2 Quick DASH scores with the average of the questionnaire scores. 
Table 1. Demographic characteristics and medical diagnosis of the participants.

\begin{tabular}{|c|c|c|c|c|}
\hline & $\mathbf{n}$ & Age (years) & Weight (kgs) & Height (cms) \\
\hline \multirow[t]{2}{*}{ Total } & 81 & $47(4)$ & $71(6)$ & $168(9)$ \\
\hline & $\begin{array}{l}41 \mathrm{M} \\
40 \mathrm{~F}\end{array}$ & $\begin{array}{l}41(18) \\
53(16)\end{array}$ & $\begin{array}{l}78(13) \\
60(8)\end{array}$ & $\begin{array}{l}175(6) \\
161(7)\end{array}$ \\
\hline Rotator cuff tendinopathy* & $\begin{array}{l}11 \mathrm{M} \\
12 \mathrm{~F}\end{array}$ & $\begin{array}{l}62(17) \\
59(14)\end{array}$ & $\begin{array}{l}79(9) \\
66(8)\end{array}$ & $\begin{array}{l}174(5) \\
160(7)\end{array}$ \\
\hline Operated broken rotator cuff & $\begin{array}{l}6 \mathrm{M} \\
6 \mathrm{~F}\end{array}$ & $\begin{array}{l}68(4) \\
65(8)\end{array}$ & $\begin{array}{l}75(4) \\
60(6)\end{array}$ & $\begin{array}{l}175(5) \\
158(6)\end{array}$ \\
\hline Instability non-operated shoulder & $\begin{array}{l}3 \mathrm{M} \\
3 \mathrm{~F}\end{array}$ & $\begin{array}{l}23(5) \\
22(5)\end{array}$ & $\begin{array}{l}68(8) \\
60(5)\end{array}$ & $\begin{array}{l}173(6) \\
165(5)\end{array}$ \\
\hline Instability operated shoulder & $\begin{array}{l}8 \mathrm{M} \\
2 \mathrm{~F}\end{array}$ & $\begin{array}{l}22(4) \\
20(5)\end{array}$ & $\begin{array}{l}66(10) \\
60(2)\end{array}$ & $\begin{array}{l}175(8) \\
165(2)\end{array}$ \\
\hline Acromioclavicular disjunction & $\begin{array}{l}6 \mathrm{M} \\
2 \mathrm{~F}\end{array}$ & $\begin{array}{l}24(4) \\
23(2)\end{array}$ & $\begin{array}{l}80(20) \\
60(2)\end{array}$ & $\begin{array}{c}178(10) \\
160(2)\end{array}$ \\
\hline Prosthesis & $1 \mathrm{~F}$ & 60 & 65 & 160 \\
\hline Sub-acromial bursitis & $\begin{array}{l}5 \mathrm{M} \\
8 \mathrm{~F}\end{array}$ & $\begin{array}{l}40(10) \\
50(10)\end{array}$ & $\begin{array}{l}75(12) \\
62(4)\end{array}$ & $\begin{array}{l}175(4) \\
162(2)\end{array}$ \\
\hline Humerus fracture & $1 \mathrm{~F}$ & 40 & 70 & 170 \\
\hline Adhesive capsulitis & $\begin{array}{l}2 \mathrm{M} \\
5 \mathrm{~F}\end{array}$ & $\begin{array}{l}45(3) \\
52(6)\end{array}$ & $\begin{array}{l}82(5) \\
65(6)\end{array}$ & $\begin{array}{l}176(4) \\
162(6)\end{array}$ \\
\hline
\end{tabular}

M: Male; F: Female.

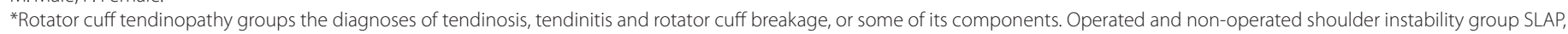
Bankart and Latarjet injuries.

Table 2. Psychometric properties of the Quick DASH questionnaire.

\begin{tabular}{|c|c|}
\hline \multicolumn{2}{|c|}{ Internal consistence $(\mathrm{n}=81$ ) } \\
\hline Cronbach's Alpha & 0.92 \\
\hline \multicolumn{2}{|c|}{ Reliability Test-Retest $(n=37)$} \\
\hline ICC & 0.95 \\
\hline $95 \%$ ICC & $0.91-0.97$ \\
\hline \multicolumn{2}{|l|}{ MDC (n=37) } \\
\hline $\mathrm{SEM}_{\mathrm{MDC}}$ & 2.2 \\
\hline SEM\% & 6.9 \\
\hline MDC & 6.9 \\
\hline MDC\% & 19.6 \\
\hline \multicolumn{2}{|l|}{ MIC $(n=23)$} \\
\hline $\mathrm{SEM}_{\mathrm{MDC}}$ & 3.4 \\
\hline SEM\% & 9.6 \\
\hline MIC & 9.0 \\
\hline $\mathrm{MIC} \%$ & 25.5 \\
\hline \multicolumn{2}{|l|}{$\operatorname{RCC}(n=34)$} \\
\hline $\mathrm{SEM}_{\mathrm{RCC}}$ & 8.3 \\
\hline SEM\% & 22.4 \\
\hline RCC & 13.2 \\
\hline $\mathrm{RCC} \%$ & 37.1 \\
\hline Sensitivity $(n=64)$ & 1.1 \\
\hline
\end{tabular}

ICC: test-retest reliability; SEMMDC: standard error of measurement for the calculation of the MDC; SEMMIC: standard error of measurement for the calculation of the MIC; SEMRCC: standard error of measurement for the calculation of the RCC; SEM\% value of the SEM expressed as a percentage; MDC: minimal detectable change; MIC: minimal important change; RCC: relevant clinical change.
Figure 1. Bland Altman graph to contrast the difference between T1 and T2 Quick DASH scores with the average of the questionnaire scores.

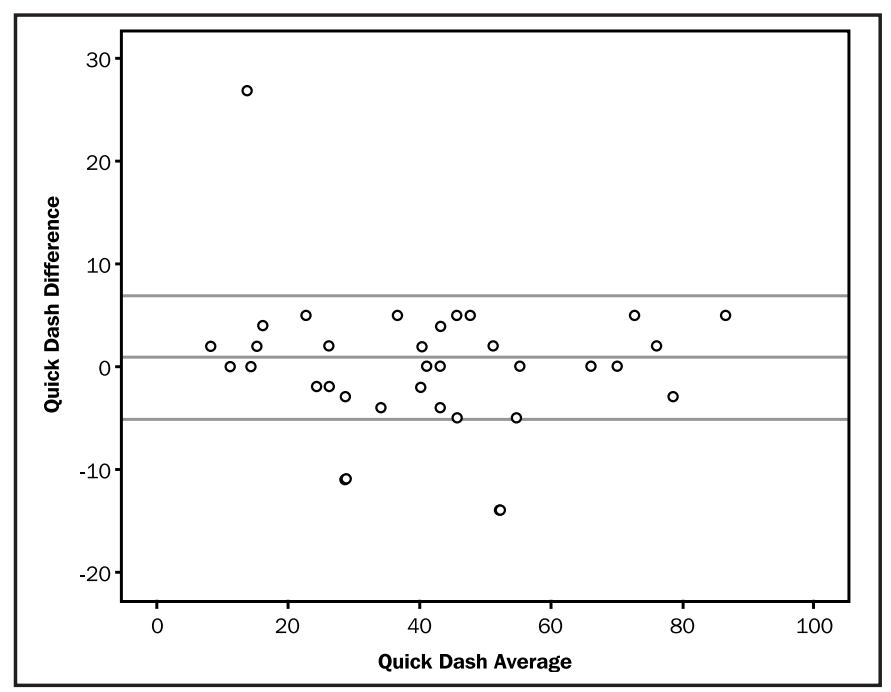

\section{Discussion}

The psychometric properties described reveal that the Quick DASH questionnaire can be used reliably in both clinical and research contexts on Chilean patients with shoulder-related pathologies. According to 
the Munro ${ }^{11}$ classification, the ICC reported reveals excellent interassessment reliability. The narrow confidence interval ensures a high level of reliability in determining the ICC. The high internal consistency reveals an extremely good correlation between each of the 11 items in terms of the questionnaire as a whole. The sensitivity established by the size of effect reveals that the questionnaire has an excellent capacity for detecting relevant changes over time. This was determined between the start and finish of 10 kinesiotherapy sessions, which patients generally took between 3 and 4 weeks to complete. When expressed as a percentage, the MDC gives a value of $20 \%$. This means that for a specific intervention to be considered as minimally relevant for Chilean patients with shoulder-related pathologies, the reduction in the score obtained in the questionnaire after intervention must be at least $20 \%$. In this study, significant clinical improvement was considered to be a variation in the questionnaire score associated to the subjective perception of being "quite better". The RCC discovered is 37\%, and can be an important reference value when it comes to classifying a surgical or conservative intervention as successful, taking into account the Quick DASH score as the outcome. Other studies ${ }^{13,15,16}$ use the MIC to consider the success or failure of an intervention. However, this variation is associated with the perception of a slight improvement, which cannot be considered a success for the patient or for the medical team. Upon comparing the psychometric properties with those of other PROM, the internal consistency is similar to that found by the American Shoulder and Elbow Surgeons (ASES) with a Cronbach's Alpha of 0.94 and a size of effect of $1.33^{17}$. Cronbach's Alpha (0.94) and ICC (0.96) are reported ${ }^{18}$ for the Western Ontario Rotator Cuff Index (WORC) questionnaire. A similar MDC to that found in this study of 6 points, is reported ${ }^{19}$ by the Western Ontario Shoulder Instability Index (WOSI), and of 12 points by the Oxford Shoulder Instability Score (OSIS).

The relevance of the study is the knowledge of the psychometric properties of a PROM validated for the Chilean population. This enables the Quick DASH to constitute an alternative in assessing the dysfunctions associated with shoulder pathologies, and the patient's perceived outcome following surgical or conservative intervention, and for this to be interpreted correctly from a methodological perspective. The study strengths are its sample size and the homogeneity of the demographic assessed. Its limitations include the factor that the gender and age of the patients may play an influencing factor in subjective perspective, and that the results were not standardised for these variables.

\section{Conclusion}

The psychometric properties of the Quick DASH questionnaire reveal that it constitutes an excellent alternative for reliable use in both clinical and research contexts on Chilean patients with shoulder-related pathologies.

\section{Conflict of interests}

The authors claim to have received no economic support or conflict of interest in the undertaking of this article.
The undersigning authors of the articles accept responsibility as stipulated by the World Association of Medical Editors http://www. wame.org/

\section{Bibliography}

1. Imaeda T, Toh S, Wada T, Uchiyama S, Okinaga S, Kusunose K. Validity of the Japanese society of the hand version of the disability of the arm, shoulder and hand (Quick Dash-JSSH) questionnaire. J Ortho Sci. 2006;11:248-53.

2. Fayad F, Lefevre M, Gautheron V, Fermanian J, Benhamou A, Roren A. Reliability, validity and responsiveness of the French version of the questionnaire Quick Disability of the Arm, Shoulder and Hand in shoulder disorders. Manual Ther. 2009;14:206-12.

3. Revicki D, Hays RD, Cella D, Sloan J. Recommended methods for determining responsiveness and minimally important differences for patient-reported outcomes. J Clin Epidemiol. 2008;61 (2):102-9.

4. Lordens G, Hartog D, Tuinebreijer W, Eygendaal D, Schep N, Verhofstad M. Minimal important change and other measurement properties of the Oxford Elbow Score and the Quick Disabilities of the Arm, Shoulder, and Hand in patients with a simple elbow dislocation; validation study alongside the multicenter FuncSiE trial. Plos One. 2017;12(9):1-17.

5. Baltzer H, Novak CB, Mc Cabe SJ. A scoping review of Disabilities of the Arm, Shoulder and Hand scores for hand and wrist conditions. J Hand Surg. 2014;39:2472-80.

6. Macdermid J, Khadilkar L, Birmingham T, Athwal G. Validity of the Quick Dash in patients with shoulder related disorders undergoing surgery. J Orthop Sports Phys Ther 2015;45(1):25-36.

7. Beaton DE, Wright JG, Katz JN. Development of the Quick Dash: a comparison of three item reduction approaches. J Bone Joint Surg. 2005;87(5):1038-43.

8. Garcia Gonzalez. G, Aguliar Sierra F, Rodriguez MC. Validación de la versión en españo de la escala de función del miembro superior abreviada: Quick Dash. Rev. Colomb. Ortop. Traumato. 2018;32(4):215-9.

9. Beaton DE, Katz JN, Fossel AH, Wright JG, Tarasuk V, Bombardier C. Measuring the whole or the parts? Validity, reliability, and responsiveness of the Disabilities of the Arm, Shoulder and Hand outcome measure in different regions of the upper extremity. $J$ Hand Ther. 2001;14(2):128-46.

10. Anthoine E, Moret L, Regnault A, Bille V, Hardouin JB. Sample size used to validate a scale: a review of publications on newly-developed patient reported outcomes measures. Health Qual Life Outcomes. 2014;12:176-86.

11. Simpson S. Creating a data análisis plan: what to consider when choosing statistics for a study. Can J Hosp Pharm. 2015;68(4)311-7.

12. Bland JM, Altman DG. Statistical methods for assessing agreement between measurements. Biochim Clin. 1987;11:399-404

13. De Vet $H C$, Terwee CB, Knol DL, Bouter $L M$. When to use agreement versus reliability measures. J Clin Epidemiol. 2006;59(10):1033-9.

14. Hopkins WG. Measures of reliability in sports medicine and science. Sports Med. 2000;30(1):1-15

15. Terwee CB, Bot SD, de Boer MR, van der Windt DA, Knol DL, Dekker J. Quality criteria were proposed for measurement properties of health status questionnaires. J Clin Epidemiol. 2007;60(1):34-42.

16. Davidson M, Keating J. Patient-reported outcome measures (PROMs): how should I interpret reports of measurement properties? A practical guide for clinicians and researchers who are not biostatisticians. Br J Sports Med. 2014;48(9):792-7.

17. Kocher MS, Horan MP, Briggs KK, Richardson TR, O'Holleran J, Hawkins RJ. Reliability, validity, and responsiveness of the American Shoulder and Elbow Surgeons subjective shoulder scale in patients with shoulder instability, rotator cuff disease, and glenohumeral arthritis. J Bone Joint Surg Am. 2005;87(9):2006-11.

18. El O, Bircan C, Gulbahar S, Demiral Y, Sahin E, Baydar M, Kizil R, Griffin S, Akalin E. The reliability and validity of the Turkish version of the Western Ontario Rotator Cuff Index Rheumatol Int. 2006;26(12):1101-8.

19. van der Linde JA, van Kampen DA, van Beers LWAH, van Deurzen DFP, Saris DBF, Terwee CB. The Responsiveness and Minimal Important Change of the Western Ontario Shoulder Instability Index and Oxford Shoulder Instability Score. J Orthop Sports Phys Ther. 2017:47(6):402-10 